\title{
O PROCESSO EDITORIAL MISCIGENADO: Silent Mangá no Brasil
}

Danielly Amatte Lopes

Janaina Freitas Silva de Araújo

\begin{abstract}
Resumo: O mangá, ou história em quadrinho produzida pelos métodos japoneses, é um produto que inicialmente foi importado para o Brasil e foi absorvido pelos brasileiros pela indústria de entretenimento e pela produção de alguns quadrinistas nacionais. O Silent Mangá é um concurso internacional com propósitos mercadológicos de ampliação da produção de mangá no mundo. O Brasil, desde a terceira rodada do concurso, em 2015, apresentou destaque com alguns produtores de histórias em quadrinhos que chegaram a vencer o concurso. Os quadrinistas que atendem todos os requisitos do concurso recebem premiação na maior categoria intitulada Grand Prix e podem ser convidados a participar de uma turma de estudos dos métodos de produção de mangá no Japão, a Masterclass. Essa pesquisa propõe-se a analisar os aspectos referentes à produção oriunda do método industrial do design gráfico nas obras dos vencedores brasileiros a fim de determinar os aspectos do design gráfico editorial que são pertinentes ao campo de atuação do designer. Tais aspectos envolvem desde a diagramação das páginas, a composição dos elementos presentes nestas, efeitos de contraste, uso de tipografia em onomatopeias, número de páginas, margens de sangria, enquadramento e emprego de grids ou malhas construtivas. A pesquisa ainda está em sua fase inicial e possui como meta apresentar os dados preliminares da pesquisa, desde a contextualização acerca dos mecanismos do concurso, como a metodologia a ser empregada para o levantamento dos dados e a relevância dos mesmos para o design no Brasil, especificamente o design editorial para histórias em quadrinhos.
\end{abstract}

Palavras-chave: editorial; design gráfico; Silent Mangá.

\section{INTRODUÇÃO: O SILENT MANGÁ E O MERCADO EDITORIAL BRASILEIRO}

Para iniciar a discursão acerca do conteúdo presente nesse trabalho, é importante compreender quais são os mecanismos que permeiam o Silent Mangá, pois o mesmo é o concurso do qual será retirado o corpus dessa pesquisa. O mercado editorial brasileiro tem crescido nos últimos anos, principalmente no que diz respeito à produção independente. A qualidade do material proveniente da produção de autoria independente cresceu não apenas em quantidade, mas em qualidade e isso se reflete na abordagem mercadológica utilizada pelas editoras de histórias em quadrinhos no Brasil. Algumas editoras como a Draco e até mesmo a própria JBC passaram a promover concursos a fim de investir em conteúdo nacional. Todavia, o processo editorial que compreende a publicação do material do quadrinista possui, por muitas vezes, abordagem dentro de elementos da construção das páginas. O Silent Mangá, por exemplo, é um concurso internacional organizado sob a ótica do mercado japonês de histórias em quadrinhos, mas que tem recebido participação de brasileiros desde sua primeira edição em 2012. E é sobre esse concurso e o conteúdo produzido por brasileiros para ele que esta pesquisa se focará. 


\subsection{APRESENTAÇÃO: O QQUE É O SILENT MANGÁ AWARD?}

O Silent Mangá Award é o maior concurso internacional de mangás atualmente, e talvez o maior englobando narrativas gráficas de modo geral. Ele ocorre em larga escala e com propósitos mercadológicos de ampliação da produção de mangá no mundo. Ele é organizado por editores e quadrinistas renomados que já chegaram ao título de senseí. Eles se uniram e criaram a Coamix. Co - editora relevante no Japão, correndo entre as maiores do país (Shueisha, Shogakugan e Kodansha).

Os responsáveis pela revista que correspondem ao cargo de jurados e de promotores do Silent Mangá, são: Nobihiko Horie (foi ex-editor chefe da revista Shonen Jump3); Tetsuo Hara (autor de Hokuto no Ken4) e Tsukasa Hojo (autor de City Hunter, Angel Heart e Cat's Eye), ambos famosos autores da década de 80; Takehiko Inoue (autor de Slam Dunk e Vagabond, e trabalhou como assistente de Tsukasa Hojo durante a produção de City Hunter).

O Silent Mangá Award lança um tema em seu website e mídias sociais e um breve briefing ${ }^{5}$ do que deve ser criado. O autor, seja ele amador ou profissional, não precisa comprovar seu currículo, ele participa por meio do envio de páginas de uma história em quadrinho segundo as diretrizes especificadas pelo concurso e - o mais importante - sem nenhum diálogo explícito por meio do uso da linguagem em palavras - categorizando essas obras, portanto, em silent (silencioso - tradução livre) mangá.

Desde 2015, as edições do concurso ganharam periodicidade semestral, com lançamento de temas duas vezes ao ano. Além dos concursos regulares, podem existir edições extras promovidas por entidades em cooperação com a equipe da Coamix Co. como foi o caso das rodadas (ou rounds) Sakura + Keep on smiling or Returning a favor (em homenagem a Fukushima) e Smile (rodada extra em solidariedade ao povo da ilha vulcânica de Kumamoto). Os prazos para produzir e enviar a obra variam entre de 4 a 5 meses.

\subsection{ALGUMAS REGRAS: COMO FUNCIONA O SILENT MANGÁ AWARD?}

O Silent Mangá Award possui, de modo geral, duas regras simples. A primeira consiste em que todas as obras não devem possuir diálogos registrados em falas diretas. A proposta do concurso é que ele possa ser abrangente e conseguir dialogar com todo o mundo, por isso não há textos ou falas das personagens. O autor necessita, portanto, apenas se concentrar na narrativa e na montagem das páginas para transmitir sua interpretação do tema proposto pelo concurso.

A segunda regra consiste no autor manter-se consistente ao tema proposto por cada edição do concurso. Os temas são abrangentes e o briefing compreende a possibilidade de que eles sejam considerados no sentido literal da palavra. A avaliação do resultado sob o critério desta segunda regra é muito mais voltado para a execução e a transmissão da mensagem proposta. Apresentações alternativas e incomuns para os temas são bemvindas, contanto que abordem a proposta inicial com objetividade e coerência, porém de um modo criativo.

\footnotetext{
1 0- história em quadrinho japonesa conhecida dessa forma por sua forma de narrativa singular e a estética na apresentação dos quadrinhos.

2 Sensei - é semelhante ao título de mestre que se recebe após o indivíduo ser reconhecido no ramo no qual atua - nesse caso específico, na produção de histórias em quadrinhos.

3 Shounen Jump - é uma revista de mangás best-selling que tem como alvo o público masculino e consiste em ter várias cenas de ação e comédia. Já chegou a vender 7 milhões de exemplares por semana.

4 Hokuto no Ken, City Hunter, Angel Heart e Cat's Eye - mangás que foram alguns dos maiores clássicos da década de 80.

5 Briefing - etapa do processo editorial que corresponde a apresentação de diversas abordagens ou sub propostas dentro do tema principal.
} 
No quadro 01 são pontuadas algumas outras regras, algumas que não foram escritas e confirmadas no website, mas que foram oriundas de troca de informações entre participantes que já venceram o concurso e que agora fazem parte de um grupo de brasileiros (Masterclass6) que foi convidado a ir ao Japão e conhecer o método de produção japonês para a editora. Outras regras são oficiais e já foram divulgadas no website ou comentadas durante os vídeos de orientação - publicados pela própria equipe editorial do Silent Mangá Award - sobre como construir a obra a ser enviada.

Quadro 01 - Lista de algumas outras regras que são divulgadas entre quadrinistas brasileiros, algumas que já foram publicadas na página de divulgação do concurso e outras que são comentadas em entrevistas e matérias entre os vencedores e a equipe editorial do concurso e da revista. Fonte: Elaborado pelo autor, com base na pesquisa realizada.

\begin{tabular}{|c|l|}
\hline \multicolumn{2}{|c|}{ Outras Regras do Silent Mangá Award (2014-2017) } \\
\hline $\mathbf{1}$ & Podem ser usadas onomatopeias nas obras enviadas; \\
\hline $\mathbf{2}$ & $\begin{array}{l}\text { Podem surgir temas duplos para confecção da obra. } \\
\text { Exemplos: Silent Mangá Award 5ạ edição (2016): “Friendship + Communication Tool”; e o } \\
\text { Returning a favor". }\end{array}$ \\
\hline $\mathbf{3}$ & Limite de páginas (a partir da 8a rodada - 2017): 16 páginas. \\
\hline $\mathbf{4}$ & $\begin{array}{l}\text { Não há restrição do número de participantes por obra, mas apenas um do grupo deve ser } \\
\text { indicado como representante do mesmo e este é quem realiza o envio da obra. }\end{array}$ \\
\hline $\mathbf{5}$ & Sentido de leitura oriental. \\
\hline $\mathbf{6}$ & Obra, de preferência, preto e branco - pois será impressa assim para avaliação. \\
\hline
\end{tabular}

Também é importante destacar as colocações mais tradicionais do Silent Mangá Award. Tradicionais, pois, no decorrer dos anos do concurso, foram adicionadas outras categorias, assim como algumas novas sugestões de regras para a produção das obras. Elas são: Grand Prix; Grand Prix Runner Up; Excellence Award; Excellence Runner Up; e Honorable Mention. Entre essas, serão consideradas as quatro primeiras, respectivamente, pois a última - menção honrosa (tradução livre) - será considerada como uma indicação simbólica pelo esforço do quadrinista em participar do concurso. As quatro primeiras serão consideradas para a finalidade dessa pesquisa, devido aos requisitos que o participante deve alcançar para chegar a tais colocações.

As premiações podem variar entre uma média de 25 vencedores. Todavia, esse modelo de premiação também não é engessado. A comissão que organiza e os jurados do concurso realizam a avaliação segundo a quantidade de obras enviadas e a qualidade das mesmas segundo os critérios estabelecidos por eles. Não há um limite imposto também ao número de premiados em cada categoria. Há edições com mais de um vencedor em Grand Prix ou de quatro a dez vencedores na categoria Excellence Award.

Todas as categorias citadas anteriormente são premiadas em dinheiro e publicadas no SMA! Web Magazine. O valor das premiações pode chegar entre R\$ 14.463,42 a RS 289,28 7. A visibilidade, contudo, é dada a todos os quadrinhos que foram enviados. No website é possível encontrar um mapa mundial com todas as publicações por região em que foram enviadas. Não é possível dispor de todos os valores de envios com exatidão por país, pois desde o SMA 7ạ edição foi contabilizada cerca de 2.900 histórias (Figura 1).

6 Masterclass - é usado pela proposta do concurso do Silent Mangá Award para designar um quadrinista ou uma turma de quadrinistas reconhecidos pela produção no estilo japonês de produção de quadrinhos para a editora Coamix Co.

7 Segundo cotação do iene - moeda japonesa - de 28 de agosto de 2017. 
Figura 1-Mapa mundial de histórias em quadrinhos enviadas para o Silent Mangá Award. Fonte: http://www. manga-audition.com/silent-manga-guide/

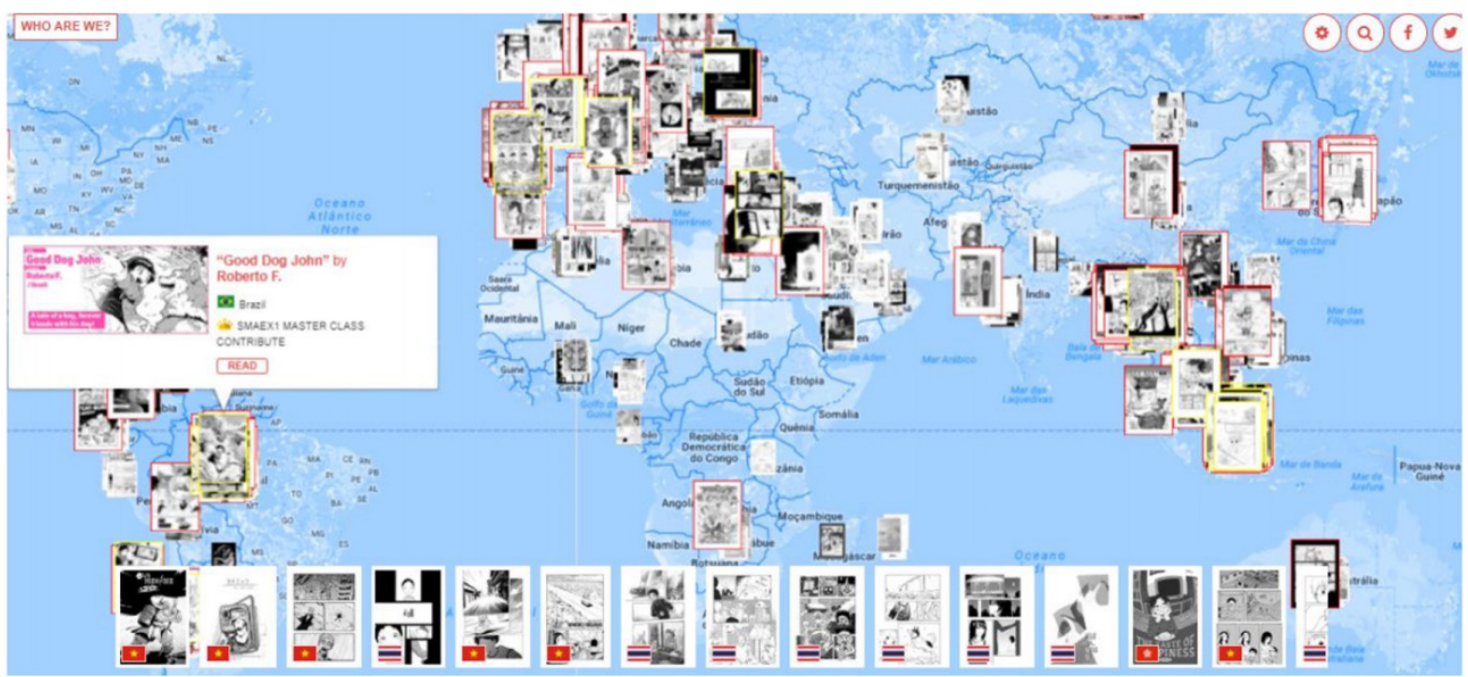

\subsection{ENTRE AS CAMADAS DO MANGÁ: OUUAL O PAPEL DO DESIGNER?}

Além de uma fonte de entretenimento para o público (LUYTEN, 2012), o mangá é didático, e é objeto de pesquisa de diversos ramos das ciências, sejam elas sociais, antropológicas, linguística ou estudos literários, na área da psicológica ou nas práticas docentes nas licenciaturas (VERGUEIRO, 2017; GROENSTEEN, 2004; HATFIELD, 2009). Segundo Borges (2016), o mangá é fonte de diversas camadas de imersão do conhecimento, sendo estas pertinentes à aproximação de pesquisadores distintos. 0 design, portanto, se aproxima de uma destas camadas pela ótica do projeto gráfico editorial.

Contudo, segundo Barbieri (2017), apenas ao designer compete o papel de configurar a organização dos elementos deste para o mercado de maneira a torna-lo de fato um produto. Ou seja, o papel do designer é reconhecido no processo editorial pelo núcleo de pesquisas acadêmicas com foco nos quadrinhos como objeto de pesquisa. Todavia, não é possível identificar com frequência análises mais profundas do ponto de vista que compete à área específica do design sobre o objeto de estudo - histórias em quadrinhos. Esse efeito pode ocorrer devido à escassez de informações que transitam entre editoras nacionais e os pesquisadores.

Segundo o processo editorial japonês para o Silent Mangá Award, as obras são avaliadas sob a perspectiva de alguns critérios. São eles: arte, personagens, composição, história e ideia. Como muitos dos aspectos destes podem ser considerados subjetivos, esta pesquisa propõe-se a analisar as obras do Silent Mangá Award produzidas por brasileiras sobre elementos que são pertinentes do conhecimento do design.

Ainda considerando o papel do designer nessa pesquisa, considerou-se que, assim como descreve Sousanis (2015), o emprego condicionado da linguagem escrita em obras gráficas muitas vezes pode funcionar como uma barreira para a transmissão do conteúdo. Essa mesma barreira não se encontra nas obras do Silent Mangá Award que, assim como o nome já sugere, são mangás silenciosos - assim como a obra de Gon (Tanaka, 2004), lançado no Brasil pela editora Conrad.

\section{O PROBLEMA: DESIGN EDITORIAL PARA QUUADRINHOS (MANGÁ)}

O mangá, ou história em quadrinho produzida pelos métodos japoneses, é um produto 
que inicialmente foi importado para o Brasil e foi absorvido pelos pela indústria de entretenimento e por alguns quadrinistas nacionais (BRAGA JR., 2011; MOLINÉ, 2004; CHINEN, 2015; LUYTEN, 2000).

O Silent Mangá possui propósitos mercadológicos de ampliação da produção de mangá no mundo. O Brasil, desde 2015, apresentou destaque com algumas histórias em quadrinhos, a exemplo das obras do brasileiro Ichirou, premiado duas vezes seguidas com o maior título do concurso (Grand Prix). A partir de então, competidores nacionais foram motivados a participar.

Essa pesquisa propõe-se a analisar os aspectos da produção oriunda do método industrial do design gráfico nas obras de brasileiros que alcançaram as principais titulações desse concurso (Grand Prix, Grand Prix Runner Up, Excellence Award e Excellence Award Runner Up).

Tais aspectos envolvem desde a diagramação das páginas a composição dos elementos presentes nestas, efeitos de contraste, uso de tipografia em onomatopeias, número de páginas, margens de sangria, enquadramento e emprego de grids ou malhas construtivas. Essa proposta visa apresentar como tais elementos que são provenientes de um estudo do design gráfico foram aplicados por meio de uma produção nacional brasileira para o concurso cuja análise e julgamento baseiam-se no método de produção mercadológico japonês.

\section{ELEMENTOS GRÁFICOS PELA ÓTICA DO DESIGN PARA MANGÁ}

Diante da problemática apontada e discutida em parte anteriormente, essa pesquisa justifica-se pelo ineditismo sob o ponto de vista do design que contempla as produções brasileiras de histórias em quadrinhos para um mercado internacional, prioritariamente japonês.

A escolha do concurso Silent Mangá Award como objeto desta pesquisa deu-se pela familiaridade com o mesmo, pelo conhecimento prático acerca de algumas das rodadas do concurso e dos mecanismos de produção de mangás. Todavia, a configuração do corpus para o desenvolvido da pesquisa foi feita segundo a relevância que o mesmo concurso possui para o mercado editorial de mangás no Brasil, sendo este país o que possui a maior colônia de imigrantes japoneses (LUYTEN, 2000; MOLINÉ, 2004).

Não obstante, as obras enviadas para este concurso possuem uma característica em peculiar em não utilizarem a linguagem escrita. A ausência dela pode servir, inclusive, como o rompimento da barreira para a comunicação, tornando tais produções mais abrangentes de compreensão para todo o mundo (SOUSANIS, 2015).

Uma das obras já comentadas anteriormente nesse artigo pode ser observada na Figura 2, que é o mangá de Masashi Tanaka (2004), Gon. 0 mangá foi trazido para o Brasil e conta sobre as aventuras de um pequeno dinossauro na natureza. 0 veículo de transmissão da linguagem é a própria imagem, portanto, é possível acompanhar a narrativa por meio do desenho e da representação gráfica dos personagens e do cenário, sem o auxílio de balonagem ou tipografia específica. 
Figura 2 - Recorte do mangá Gon de Masashi Tanaka, publicado em 2004.
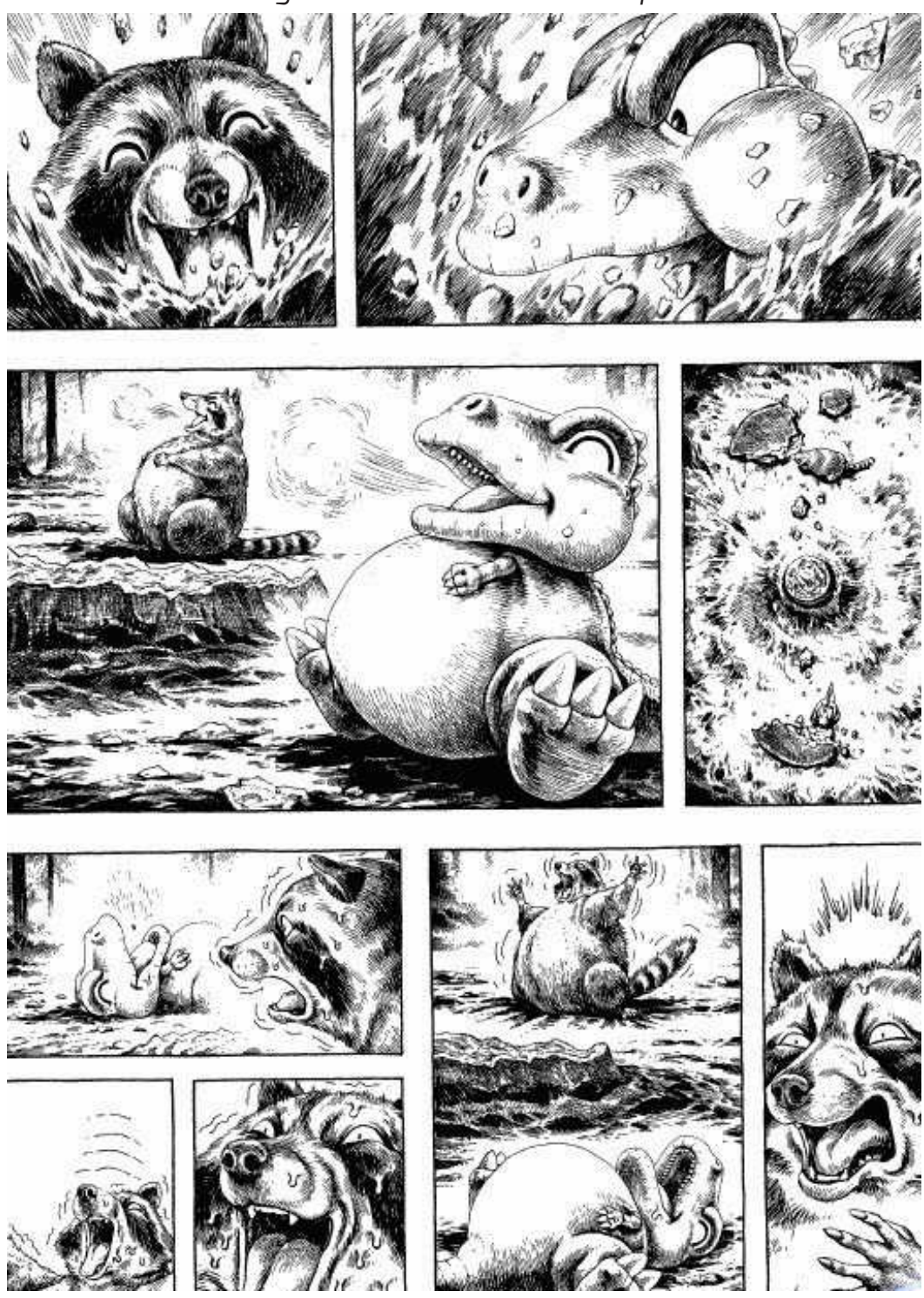

\section{A IMPORTÂNCIA DA ANÁLISE DE CONTEÚDO DO SILENT MANGÁ}

Analisar a produção brasileira para o concurso internacional do Silent Mangá Award sob a ótica do design diante dos elementos que compõem uma obra gráfica pelo processo editorial de histórias em quadrinhos japonesas (mangás) é relevante por alguns aspectos. O concurso oriundo do Japão é um dos maiores do mundo, contando atualmente com edições duas vezes ao ano, além de rodadas extras. 0 mesmo também aborda alguns aspectos do processo gráfico de editoração, como a apresentação de um tema para cada rodada do concurso que é acompanhado por um briefing. Abaixo se pode observar no Quadro 2 a relação entre os temas lançados desde 2012 pelo concurso Silent Mangá Award e a colocação dos brasileiros em relação as principais premiações do mesmo. 
Quadro 2 - Relação entre as edições do Silent Mangá Award (SMA), suas respectivas edições e competidores brasileiros premiados. Fonte: Elaborado pelo autor, com base na pesquisa realizada.

\begin{tabular}{|c|c|c|c|c|c|}
\hline 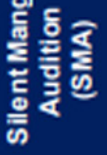 & Tema & Publicaçāo & Competidores & Premiados & $\begin{array}{l}\text { Competidores } \\
\text { Brasileiros } \\
\text { Premiados }\end{array}$ \\
\hline$\sum_{\infty}^{\infty}$ & Love Letter & $\begin{array}{c}2013 \\
\text { (junho) }\end{array}$ & 514 & 26 & 0 \\
\hline$\sum_{\infty}^{\infty}$ & $\begin{array}{c}\text { The Finest } \\
\text { Smile }\end{array}$ & $\begin{array}{l}2014 \\
\text { (junho) }\end{array}$ & 604 & 28 & 1 (Grand Prix) \\
\hline$\sum_{\infty}^{\infty}$ & Mother & $\begin{array}{c}2015 \\
\text { (junho) }\end{array}$ & 803 & 44 & $\begin{array}{c}1 \text { (Grand Prix) } \\
1 \text { (Excellence } \\
\text { Award) } \\
1 \text { (Excellence } \\
\text { Award Runner up) }\end{array}$ \\
\hline$\sum_{\infty}^{+}$ & A Charming Gift & $\begin{array}{c}2015 \\
\text { (dezembro) }\end{array}$ & 448 & 20 & $\begin{array}{c}1 \text { (Grand Prix } \\
\text { Runner up) }\end{array}$ \\
\hline $\begin{array}{l}\text { ய } \\
\sum_{\omega}-\end{array}$ & $\begin{array}{c}\text { Sakura + Keep } \\
\text { on smiling or } \\
\text { Returning a } \\
\text { favor }\end{array}$ & 2016 (abril) & 216 & 28 & $\begin{array}{l}1 \text { (Grand Prix } \\
\text { Runner up) }\end{array}$ \\
\hline$\sum_{\infty}^{\infty}$ & $\begin{array}{c}\text { Friendship + } \\
\text { Communication } \\
\text { Tool }\end{array}$ & $\begin{array}{c}2016 \\
\text { (junho) }\end{array}$ & 602 & 25 & $\begin{array}{c}1 \text { (Excellence } \\
\text { Award) }\end{array}$ \\
\hline$\sum_{\text {ஸ }}^{\infty}$ & Childhood & $\begin{array}{c}2016 \\
\text { (dezembro) }\end{array}$ & 531 & 26 & $\begin{array}{l}1 \text { (Grand Prix } \\
\text { Runner Up) }\end{array}$ \\
\hline$\sum_{\text {แ }}^{\frac{x}{4}}$ & Smile & 2017 (abril) & 209 & 39 & $\begin{array}{c}1 \text { (Excellence } \\
\text { Award) }\end{array}$ \\
\hline$\sum_{\infty}^{\infty}$ & $\begin{array}{c}\text { Unforgettable } \\
\text { Taste }\end{array}$ & 2017 (julho) & 608 & 26 & $\begin{array}{l}1 \text { (Grand Prix } \\
\text { Runner Up) }\end{array}$ \\
\hline
\end{tabular}

Destaca-se, todavia, o SMA3, com 3 brasileiros no ranking de premiados nas principais categorias do concurso. 
Quando 3 - Informações acerca das obras que compõem o corpus da pesquisa. Fonte: Elaborado pelo autor, com base na pesquisa realizada.

\begin{tabular}{|c|c|c|c|}
\hline Premiados (Obra e Autor) & Categoria & Ano & Informações \\
\hline $\begin{array}{c}\text { SMA } 2 \text { - The Finest Smile } \\
\text { Título: Father's Gift } \\
\text { ICHIROU }\end{array}$ & Grand Prix & 2014 & $\begin{array}{l}15 \text { páginas; média de } 2-6 \text { quadros por página; } \\
\text { formato B4; grid tradicional; possui tipografia } \\
\text { no título; elementos especiais: uso de } \\
\text { retícula, uso de repetição de enquadamento, } \\
\text { uso de zoom in e uso de efeito Splash Page. }\end{array}$ \\
\hline $\begin{array}{c}\text { SMA 3-Mother } \\
\text { Título: Homesick Alien } \\
\text { ICHIROU }\end{array}$ & Grand Prix & 2015 & $\begin{array}{l}11 \text { páginas; média de 1-8 quadros por página; } \\
\text { grid intermediário; tipografia no título; } \\
\text { elementos especiais: repetição de quadros, } \\
\text { zoom out e zoom in, plonge e contra-plonge, } \\
\text { efeito Splash Page. }\end{array}$ \\
\hline $\begin{array}{l}\text { SMA } 3 \text { - Mother } \\
\text { Título: } 6 \text { Reasons } \\
\text { ROBERTO }\end{array}$ & $\begin{array}{c}\text { Excellence } \\
\text { Award }\end{array}$ & 2015 & $\begin{array}{l}16 \text { páginas; média de } 1-8 \text { quadros por página; } \\
\text { grid tradicional e intermediário; uso de } \\
\text { tipografia no título; elementos especiais: } \\
\text { Splash Page. }\end{array}$ \\
\hline $\begin{array}{l}\text { SMA 3-Mother } \\
\text { Título: Mothercracy } \\
\text { EUDETENIS }\end{array}$ & $\begin{array}{l}\text { Excellence } \\
\text { Award } \\
\text { Runner up }\end{array}$ & 2015 & $\begin{array}{l}13 \text { páginas; média de } 1-6 \text { quadros por página; } \\
\text { grid tradicional; tipografia no título; } \\
\text { elementos especiais: plonge e contra-plonge, } \\
\text { repetição de quadros, Splash Page. }\end{array}$ \\
\hline $\begin{array}{l}\text { A Charming Gift } \\
\text { Título: Play } \\
\text { ROBERTO }\end{array}$ & $\begin{array}{l}\text { Grand Prix } \\
\text { Runner up }\end{array}$ & 2015 & $\begin{array}{l}13 \text { páginas; média de } 1-10 \text { quadros por } \\
\text { página; grid tradicional e experimental; } \\
\text { tipografia no título; elementos especiais: } \\
\text { plonge e contra-plonge, repetição de cenas, } \\
\text { Splash Page, uso de indicativo do "fim" da } \\
\text { história. }\end{array}$ \\
\hline $\begin{array}{l}\text { Sakura }+ \text { Keep on smiling or } \\
\text { Returning a favor } \\
\text { Título: Lend a Hand } \\
\text { MAX ANDRADE }\end{array}$ & $\begin{array}{l}\text { Grand Prix } \\
\text { Runner up }\end{array}$ & 2016 & $\begin{array}{l}13 \text { páginas; média de 1-8 quadros por página; } \\
\text { grid tradicional; uso de tipografia no título; } \\
\text { elementos especiais: zoom in, sequência de } \\
\text { cenas, plonge e contra-plonge, Splash Page, } \\
\text { uso do indicativo do "fim" da história. }\end{array}$ \\
\hline $\begin{array}{c}\text { Friendship + Communication Tool } \\
\text { Título: Try Again? } \\
\text { ZAZO AGUIAR }\end{array}$ & $\begin{array}{c}\text { Excellence } \\
\text { Award }\end{array}$ & 2016 & $\begin{array}{l}8 \text { páginas; média de } 3-6 \text { quadros por página; } \\
\text { grid tradicional e intermediário; uso de } \\
\text { tipografia no título; elementos especiais: } \\
\text { contra-plonge e plonge. }\end{array}$ \\
\hline $\begin{array}{l}\text { Childhood } \\
\text { Título: Forbidden } \\
\text { YOS }\end{array}$ & $\begin{array}{l}\text { Grand Prix } \\
\text { Runner Up }\end{array}$ & 2016 & $\begin{array}{l}17 \text { páginas; média de 1-8 quadros por página; } \\
\text { grid tradicional; uso de tipografia no título; } \\
\text { elementos especiais: zoom in, plonge, contra- } \\
\text { plonge, repetição de cenas, Splash Page. }\end{array}$ \\
\hline $\begin{array}{c}\text { Smile } \\
\text { Título: Legendary Warrior } \\
\text { FABIANO FERREIRA }\end{array}$ & $\begin{array}{c}\text { Excellence } \\
\text { Award }\end{array}$ & 2017 & $\begin{array}{l}12 \text { páginas; média de 1-6 quadros por página; } \\
\text { grid tradicional; uso de tipografia no título; } \\
\text { elementos especiais: plonge, contra-plonge, } \\
\text { repetição de cenas, Splash Page, uso de } \\
\text { indicativo do "fim" da história. }\end{array}$ \\
\hline $\begin{array}{c}\text { Unforgettable Taste } \\
\text { Título: Grandma's Flavor } \\
\text { EUDETENIS }\end{array}$ & $\begin{array}{l}\text { Grand Prix } \\
\text { Runner Up }\end{array}$ & 2017 & $\begin{array}{l}39 \text { páginas; média de 1-6 quadros por página; } \\
\text { grid tradicional e intermediário; uso de } \\
\text { tipografia para o título; elementos especiais: } \\
\text { plonge, repetição de cenas, Splash Page, } \\
\text { Página Única, Zoom in. }\end{array}$ \\
\hline
\end{tabular}

A partir de então, os brasileiros não deixaram de ser premiados. Outro destaque encontra-se no SMA7 com a obra vencedora da dupla Eudetenis - uma dupla brasileira que já havia participado antes do concurso, mas não alcançou uma premiação tão alta quanto Grand Prix Runner Up. A obra deles ganha destaque, pois curiosamente após sua participação, venceram o concurso com uma história de 38 páginas - o máximo de páginas em uma obra já premiada pelo concurso. A partir dessa rodada, a comissão do concurso publicou uma nova regra sobre o número máximo de páginas (que passou a ser 16). Para dar continuidade a essa análise das obras vencedoras que fazem parte do corpus de análise da pesquisa, observa-se o Quadro 3.

\section{DADOS PREMILIARES: ELEMENTOS GRÁFICOS ENCONTRADOS}


O processo de desenvolvimento da pesquisa é híbrido e linear. A análise de conteúdo é compartida e a metodologia híbrida entre os aspectos do design gráfico editorial abordados por Peón (2009) e Koberg \& Bagnall (1971), considerando o último pela proposta de validação das obras desenvolvidas posteriormente com os dados obtidos por meio desse levantamento preliminar.

Como a pesquisa está em sua fase inicial, o presente artigo identifica apenas os elementos da produção gráfica editorial que são empregados nas obras brasileiras premiadas e pelo Silent Mangá Award - apontadas no Quadro anterior. Observa-se, portanto, a prevalência de alguns elementos, principalmente especiais, que estão presentes nas obras vencedoras do concurso. São eles: o uso de tipografia no título da obra; uso de Splash Page ${ }^{8}$; grid predominantemente tradicional; uso frequente de plonges e contra-plonges; uso de zoom in; e uso de repetição de cenas.

Espera-se com esta pesquisa desenvolver uma conformidade com os dados para o processo editorial voltado para quadrinhos no Brasil que utilizam do método de produção japonês (o voltado para mangá). Com esses dados oriundos da comparação e análise de conteúdo, será possível pontuar algumas convergências entre a lógica utilizada na concepção do design editorial (ZAPPATERRA, 2008) e o desenvolvimento de quadrinhos como objeto da indústria de entretenimento (MCCLOUD, 1995).

\section{REFERÊNCIAS}

BARBIERI, D. A Linguagem dos Quadrinhos. São Paulo: Editora Peirópolis. 2017.

BORGES, P. M. Mangá, Estética bidimensional e deslocamentos culturais. São Paulo: Editora Intermeios. 2016.

BRAGA JR., A. X. Desvendando o Mangá Nacional. Maceió: Edufal. 2011.

BRANDÃO, P. J. A. Movimentos e quadriláteros: a relação entre histórias em quadrinhos e silêncio. São Paulo. Anais das 2as Jornadas Internacionais de Quadrinhos. Escola de Comunicações e Artes - Universidade de São Paulo. 2013. Acessado em: 4 de ago de 2017. Disponível em: < http://www2.eca.usp.br/anaisZajornada/anaisZasjornadas.php >

CHINEN, N. Linguagem HQ̣s: conceitos básicos. São Paulo: Editora Criativo. 2015.

COAMIX Co. Editora do Silent Mangá Award. Acessado em: 10 de ago 2017. Disponível em: < http://www.coamix.co.jp/>

EISNER, W. Quadrinhos e arte sequencial. Tradução Luis Carlos Borges. São Paulo. Editora Martins Fontes. 1989.

GROENSTEEN, T. História em quadrinhos: essa desconhecida arte popular. João Pessoa. Editora Marca de Fantasia, 2004.

HATFIELD, C. An art of tensions. In: HEER, J. WORCESTER, K. (Orgs.). A comics studies reader. Jackson: University Pree of Mississippi, 2009.

JENKINS, H. Invasores do Texto. Fãs e Cultura Participativa. São Paulo. Editora Marsupial. 2015.

KOBERG, D. \& BAGNALL, J. The All New Universal Traveler: A Soft-Systems Guide To Creativity, Problem-Solving, And The Process Of Reaching Goals. Los Altos, CA: William Kaufmann, Inc. 1971. 
LUYTEN, S. B. Mangá: o poder dos quadrinhos japoneses. 2a edição. São Paulo. Hedra. 2000.

Hedra. 2012.

Mangá: o poder dos quadrinhos japoneses. 3a edição. São Paulo.

Onomatopeia, mímese do som japonês. Revista USP, São Paulo, n. 52,

p. 176-188, dez / fev de 2001-2002. Acessado em 3 de ago de out de 2017. Disponível em: < https://www.revistas.usp.br/revusp/article/view/33176/35914 >

MCCLOUD, S. Desvendando os quadrinhos. Tradução Helcio de Carvalho, Marisa do Nascimento Paro. São Paulo. Makron Books. 1995.

MOLINÉ, A. O Grande Livro dos Mangás. São Paulo: JBC, 2004.

ORLANDI, E. P. As formas do silêncio - no movimento dos sentidos. Campinas, S. R: Editora da Unicamp, 1997.

PÉON, M. L. Sistemas de Identidade Visual. $4^{\circ}$ ed. Rio de Janeiro: 2AB Editora. 2009.

SAMARA, T. Diseñar con y sin retícula. Barcelona. Editorial Gustavo Gil, SL. 2004.

SILENT Mangá Award. Acessado em: 03 de ago 2017. Disponível em: < http://www. manga-audition.com/>

SOUSANIS, N. Unflattening. Harvard. Havard University Press. 2015.

TANAKA, M. Gon vai à caça. Masashi Tanaka [ilustrações do autor] São Paulo: Editora Conrad do Brasil. 2004. Título original: Gon fights with wolf brothers. vol. 1.

VERGUEIRO, W. Pesquisa Acadêmica em Histórias em Quadrinhos. São Paulo. Editora Criativo. 2017.

ZAPPATERRA, Y. Diseño Editorial, Periódicos y Revistas. Barcelona. Editorial Gustavo Gil, SL. 2008.

Sobre as autoras:

Danielly Amatte Lopes (doutora), UFAL <danielly.lopes@fau.ufal.br>

Janaina Freitas Silva de Araújo (graduanda) UFAL < jana.f.araujo@gmail.com> 